\title{
AGRICULTURA URBANA E PERIURBANA
}

\author{
agriculture urban and periurban \\ Juliano Avelar Moura * \\ William Rodrigues Ferreira ** \\ Luciene de Barros Lorandi Silveira Lara $* * *$
}

\begin{abstract}
Resumo
O debate a respeito de uma nova concepção para o planejamento das cidades tem se acirrado a cada ano, isto em função da necessidade de reaver o atual modelo caótico de gestão do espaço urbano e as suas interações. $\mathrm{O}$ objetivo deste trabalho é expor, em linhas gerais, uma abordagem a respeito do planejamento municipal voltada para a dinâmica das relações entre o meio ambiente, o transporte e a socieconomia nos centros urbanos. Apresenta uma argumentação sobre a viabilidade da indução de modelos urbanos de produção agrícola como um programa estratégico para harmonização dos espaços urbanos, a chamada agricultura urbana e periurbana.
\end{abstract}

Palavras-chave: Planejamento urbano, Meio ambiente, Socieconomia.

\begin{abstract}
The debate regarding a new conception for the planning of the cities if has incited to each year, this in function of the necessity to recover the current chaotic model of management of the urban space and its interactions. The objective of this work is to display, in general lines, a boarding regarding the municipal planning directed toward the dynamics of the relations between the environment, the transport and the socioeconomic in the urban centers. It presents an argument on the viability of the induction of urban models of agricultural production as a strategically program for harmonization of the urban spaces, the call urban and periurbana agriculture.
\end{abstract}

Key words: Urban planning, Environment, Socieconomia.

\section{Résumé}

Le débat concernant une nouvelle conception pour la planification des villes si a incité à chaque année, à ceci en fonction de la nécessité de récupérer l'actuel modèle chaotique de gestion de l'espace urbain et leurs interactions. L'objectif de ce travail est exposer, dans des lignes générales, un abordage concernant la planification municipale tournée pour la dynamique des relations entre l'environnement, le transport et la socieconomia dans les centres urbains. Il présente un argument sur la viabilité de l'induction de modèles urbains de production agricole comme un programme stratégique pour harmonisation des espaces urbains, l'appelée agriculture urbaine et la periurbana.

Mots-clés: Planification urbaine, Environnement, Socieconomia.

(*) Prof. Dr. da Universidade Federal de Goiás - Av. Bom Pastor, SN, CEP: 76600000 - Cidade de Goiás (GO), Brasil - Tel: (+ 55 62) 33712900 - jam.loboguara@gmail.com

(**) Prof. Dr. da Universidade Federal de Uberlânidia - Instituto de Geografia - Câmpus Santa Mônica - Bloco 1H - Av. João Naves de Ávila, 2121, CEP: 38400902 - Uberlândia (MG), Brasil - Tel: (+55 34) 32394169 - wferreira@ufu.br

(***) Prof ${ }^{a}$. Dr ${ }^{\mathrm{a}}$. da Universidade Metodista de Piracicaba - Rodovia Luís Ometto km. 24, CEP: 13451900 - Santa Bárbara D’Oeste (SP), Brasil - Tel: (+ 55 19) 31241659 - luciene.lara@gmail.com 


\section{INTRODUÇÃO}

A partir da chamada "Revolução Verde" em todos os governos foi intensificado o discurso sobre a importância da produção de alimentos para solucionar o problema da fome no país. A partir de então foram criadas e implementadas até a atualidade, as políticas voltadas para a produção agrícola, sempre embasada na eficiência produtiva. Para garantir a eficiência produtiva, ficou estabelecido um aparato tecnológico e industrial para a fabricação de máquinas e implementos, fertilizantes, agrotóxicos, sementes, genética animal, ração, veículos, etc. Contudo esta evolução tecnológica não atendeu a maior parte das famílias rurais, muito em função do alto custo de acesso a essas tecnologias.

O resultado foi que várias famílias se viram excluídas desse novo cenário de produção rural, e acabaram migrando para os centros urbanos a fim de compor a grande massa de operários da indústria. Esta transição do camponês para o operário gerou forte impacto na organização dos espaços urbanos, tais como: formação das periferias sobre as áreas de preservação permanente, seja nas margens dos córregos ou morros; expansão da cidade sobre áreas antes denominadas rurais; caracterização de comércios específicos em função da cultura de origem, a exemplo os chamados mercadões; estabelecimento das redes de trânsito e transportes; etc. Podemos então, a partir do exposto, afirmar que o urbano também é rural.

A partir da década de 80 houve uma intensificação do fluxo contrário, o urbano tentar voltar para o meio rural. Esta colocação se justifica pelo crescimento das manifestações de ocupação a terra, liderada principalmente pelos movimentos de trabalhadores sem terra e sindicatos dos trabalhadores rurais, que reivindicavam o cumprimento da Constituição Federal que em seu art. $5^{\circ}$, parágrafo XXIII, preconiza que a propriedade rural deve atender a sua função social. Em momentos de crise econômica no setor urbano comumente acontece a intensificação da "fuga" dos operários egressos da indústria para o meio rural. A partir do advento que aqui chamamos de fuga operária para o meio rural, podemos afirmar que o rural também é urbano.

Somada à necessidade de aumentar a produção nacional de alimentos para uma população que cresce numa escala exponencial, está a necessidade de implementar modelos produtivos que contemplem um planejamento ambiental que satisfaça, de forma eficaz, o bem estar social e a conservação dos recursos naturais para o médio e longo prazo. $\mathrm{O}$ foco do planejamento deve ser econômico, social e ambiental.

Como um ponto estratégico para esse planejamento urbano, podemos incluir a formação do modelo urbano e periurbano de agricultura, aqui chamado de ocupação não convencional, ou seja, modelo ainda não oficializado pela maior parte das políticas públicas e que acontece nos maciços urbanos e periurbanos. É uma alternativa produtiva viável para os espaços ociosos das metrópoles, o que justifica a sua inclusão nas políticas públicas sob a alegação da sua viabilidade econômica, social e ambiental na ocupação do espaço urbano.

\section{O PLANO DIRETOR COMO FERRAMENTA PARA O PLANEJAMENTO MUNICIPAL}

O Estatuto da Cidade estabelece que a propriedade precisa cumprir uma função social, ou seja, a terra deve servir para o benefício da coletividade, e não apenas aos interesses de seu proprietário.

A função social deve ser definida no Plano Diretor. Isso quer dizer que o Plano deve definir qual é a melhor forma de usar cada pedaço do município, de forma a garantir os espaços de uso coletivo para todos, ou seja, os locais de circulação, os equipamentos públicos como as escolas, asilos, creches, casas de saúde, etc., e as áreas de proteção ambiental. Poderá de fato garantir terra adequada para todas as atividades econômicas e classes sociais, principalmente para a população de baixa renda (Resolução $n^{0} 34 / 2005$ ).

O Estatuto da Cidade diz que quando a propriedade não está cumprindo a sua função social o Plano Diretor deve pressionar para que cumpra, através de instrumentos urbanísticos. Para que se 
cumpra a sua função social o Plano Diretor deverá:

a) definir quando um imóvel é considerado subutilizado, não edificado e não utilizado, de acordo com sua função social. Por exemplo, uma propriedade localizada no centro da cidade, com infra-estrutura, dotado de equipamentos e serviços públicos como transportes, escolas, água, dentre outros, que não possui construções e não está sendo utilizada, normalmente não está cumprindo sua função social, pois está desocupada em um região onde seria desejável ocupar e adensar. Por outro lado, uma propriedade localizada em uma região de proteção ambiental, ocupada por vegetação densa e significativa, e que não possui construções está cumprindo sua função social se não estiverem densamente ocupados, se conseguirem preservar ou manter seu meio ambiente com qualidade, para que todos os municípios de uma região possam usufruir desse manancial.

b) para não virar apenas uma lista de boas intenções, o Plano tem que dizer qual é a função social de cada área, delimitar isso no mapa da cidade e aplicar os instrumentos para induzir o proprietário a cumprir sua função social . Esses instrumentos são: o parcelamento, edificação ou utilização compulsórios; IPTU progressivo no tempo; e desapropriação com pagamento em títulos da dívida pública. Podem existir outros, desde que atendam aos objetivos do Plano e sejam decididos por todos quais devem existir no município. Citamos: direito de preempção, outorga onerosa de construir, operações urbanas consorciadas, transferência do direito de construir.

\section{O ZEIS}

As Zonas Especiais de Interesse Social são as áreas da cidade que são destinadas pelo Plano Diretor para abrigar moradia popular, reservar terrenos ou prédios vazios para moradia popular em áreas onde já existe boa infra-estrutura . Uma área subutilizada num aglomerado urbano poderá ser uma ZEIS facilitar a regularização de áreas ocupadas. Quando uma área ocupada vira ZEIS, seus moradores conseguem regularizar sua moradia de forma mais rápida, e também fica mais fácil lutar por melhorias para aquela região.

Para a consolidação das Zonas Especiais de Interesse Social o Plano Diretor estabelecer algumas premissas:

- Definição de critérios para a demarcação das áreas de ZEIS;

- Definir o padrão tido como baixa renda;

- Prever a elaboração dos programas e planos de urbanização de cada ZEIS garantindo a participação popular. Os planos e programas devem contemplar o respeito a recuperação e a conservação do meio ambiente;

- Estabelecer as prioridades urbanísticas;

- Definir a participação população na gestão das áreas.

A implementação do ZEIS somada a uma gestão efetiva poderá proporcionar uma significativa melhoria no conforto ambiental dos maciços urbanos a partir da diversificação do espaço urbanístico com a consolidação de parques, jardins, áreas de lazer e cultura, e viabilização dos nichos alternativos de comércio e consumo.

\section{OS PRINCIPAIS TEMAS DA GESTÃO AMBIENTAL MUNICIPAL}

A Constituição Federal de 1988 torna obrigatório, em seu artigo 182, que cada cidade com mais de 20000 habitantes tenha um Plano Diretor aprovado pela Câmara Municipal, que seja seu instrumento de política de desenvolvimento e de expansão urbana. Esses planos devem apresentar-se coerentes e sinérgicos com os planos de gestão ambiental, pois é impossível considerarem-se 
as perspectivas e propostas para uma área urbana abstraindo-se de suas variáveis ambientais. Em especial, o planejamento que leva em conta o meio ambiente deverá detectar os pontos de vulnerabilidade e as áreas de riscos ambientais para o assentamento da população e dos empreendimentos, as áreas vocacionais para atividades que, por sua vez, podem determinar distintos graus de adensamento, as descontinuidades no tecido urbano, os eixos de expansão e de restrições devidas a fatores ambientais como, por exemplo, cursos d'água ou direções predominantes dos ventos, entre tantos outros (Philipp Jr. et al. 1999).

Os resultados do planejamento, para serem efetivos, devem por sua vez serem apresentados para o conhecimento da população e por ela aprovados e apropriados, para tornar mais fácil sua implantação, naturalmente através dos foros apropriados e que determinem sua seqüência e acompanhamento, seja fiscalizando as posturas e condutas dos empreendedores, seja zelando para que a população não se assente em locais ou de maneiras inadequadas.

As cidades ou áreas de assentamento espontâneo, sem planejamento ou diretrizes traçadas, são frequentemente cheias de dificuldades no que concerne à execução de políticas e planos ambientais; surge daí a preemência de, sempre que possível, ter elaborados o Plano Diretor de Desenvolvimento as diretrizes ambientais. Muitos locais, no Brasil e em outros paises do mundo têm utilizado uma variante de tal processo que é a elaboração de sua agenda 21 local, com resultados extremamente positivos. Entretanto, nem o Brasil e nem os Estados, têm a sua.

Em qualquer dos casos, a divulgação e legitimação dos resultados são fundamentais, tanto nos casos em que o município utilize sua capacidade disponível para elaborar esse planejamento ambiental, quanto nos casos em que os mesmos sejam contratados ou parcialmente terceirizados.

No caso específico dos complexos metropolitanos é crescente a preocupação do planejamento, a definição de áreas verdes voltadas para harmonização do espaço urbano e melhoria da qualidade ambiental.

\section{ÁREAS VERDES: Criação e Manutenção}

Philipp Jr. (1999) afirma que os conjuntos urbanos necessitam de descontinuidade de ocupação a fim de que os espaços sociais não se vejam comprometidos em sua função primordial que é a de ser o lugar de viver do homem e das comunidades, o que significa: dormir, trabalhar, ter momentos de lazer, relacionar-se.

A estas descontinuidades Philipp Jr. (1999) denomina áreas verdes ou azuis quando se tratar de corpos d'água e que se dividem em grandes e pequenas.

As grandes:

- os parques municipais ou similares que devem cumprir as funções: de pulmão quanto a circulação atmosférica e à iluminação urbana; de preservação de uma parte significativa da paisagem natural original ou recomposta e com valor estético ou científico; a de espaço para educação ambiental e convívio; e recreação e lazer.

As pequenas:

- áreas verdes representadas pelos jardins, praças ou parques lineares ao longo de fundos de vales urbanizados.

Considerando-se as necessidades de ser colocado em linha este processo de gestão, com a perspectiva da sustentabilidade dos assentamentos humanos, faz-se urgente enfrentar os dilemas da modernização do processo de planejamento urbano e ambiental, e das estratégias de gestão ambiental para a aplicação de instrumentos preventivos, de controle, e mitigação de impactos ambientais nos espaços urbanos mais eficientes e com maior eficácia nos resultados (Máglio, 1999). 


\section{ESPAÇO URBANO E MEIO AMBIENTE}

Ribeiro et al (1995) expõe o termo "gestão urbana ecologizada" ao referir-se sobre a introdução da dimensão ambiental em cada uma e em todas as unidades da administração local. Ressalta a importância em descentralizar verticalmente a questão ambiental no nível municipal para o nível das administrações regionais, quarteirões, unidades de vizinhança e até mesmo o nível doméstico.

No que cabe a argumentação do estudo em questão, Ribeiro (1995) enfatiza o argumento específico sobre o transporte, a circulação e o trânsito. Afirma que os transportes são os principais fatores de poluição sonora e atmosférica, e sinaliza uma possível medida para mitigação em seu relato:

...o uso intensivo do transporte coletivo, preferencialmente o individual ou o uso de modos de transportes não-poluentes, como bicicletas, para os percursos mais curtos, são medidas que ajudam a reduzir seus efeitos ambientais negativos...

Ainda sobre a poluição sonora, segundo (Ribeiro,1995), podemos afirmar que trás um incômodo cotidiano e danos à saúde, e gerada principalmente por atividades noturnas, industriais, comerciais, e pelo transporte coletivo e individual.

Pons e Reynés (1991) afirmam que qualquer tipo de movimentação urbana acontece por uma forma de transporte, contudo a questão principal é a análise dos efeitos desse transporte no espaço. Ela poderá se dar de forma plena, quando atender os padrões satisfatórios de qualidade ambiental, ou de forma precária quando comprometer a qualidade do espaço e suas relações. A disponibilidade dos transportes é proporcional à infra-estrutura distribuída ao longo do território - espaço -, uma deficiência no planejamento desta infra-estrutura acarretaria a concentração de problemas ambientais urbanos tais como:

- desconforto decorrente da poluição atmosférica por CO;

- saturação dos espaços urbanos devido à concentração da atividades humanas no entorno da infra-estrutura de transporte;

- centralização dos recursos públicos e privados em uma determinada área geográfica, provocando um desequilíbrio espacial entre a oferta e a demanda;

- falta de infra-estrutura alternativa ao modelo histórico predominante;

- incentivo à especulação imobiliária;

- possibilidade na formação de cartéis dos grupos dominantes no transporte de passageiros;

- dificuldade na mobilidade de pessoas e cargas devido a saturação dos espaços;

- centralização das atividades econômicas o que ocasiona o caos no sistema de trânsito;

- concentração de problemas sociais tais como roubos, latrocínios, comércio de drogas;

- formação de mercados informais;

- desconforto pela intensificação da poluição sonora;

- redução das Zonas Especiais de Interesses Sociais (ZEIS);

- aumento do conflito entre os elementos de trânsito;

- depreciação do patrimônio público e privado;

- concentração dos problemas de saneamento e habitação; 
- favorecimento da ocupação ilegal e de risco nas áreas periféricas;

- descaracterização parcial ou total do espaço;

- aumento dos acidentes de trânsito;

- impermeabilização do solo;

- aumento do lixo sólido;

- diminuição da circulação de ar pelo efeito "quebra ventos";

- interferência direta na flora e fauna da região;

- aumento da dependência por energia.

Outras conseqüências decorrentes da falta ou do planejamento superficial dos transportes poderiam ser adicionadas às já citadas, contudo, a preocupação principal surge pela indicação de um cenário futuro ainda mais insalubre que o atual. A dinâmica econômica aponta para uma relação exponencial do uso dos espaços urbanos - Coeteris Paribus - sob a situação do aumento das disponibilidades (produção) em função do aumento da demanda de uma população, que outrora, estava marginalizada no sistema. Em outras palavras podemos afirmar que a necessidade de transportes, seja individual, coletivo ou de cargas aumentará (Sanches Junior, 2008). Levantamento da ANTP/BNDES (2007) mostra que à medida que acontece o aumento da renda familiar há também o aumento da demanda linear diária em $\mathrm{km}$ da necessidade de transporte público e individual.

Na observação levantada pelo Ministério das Cidades (2006) descreve a realidade da transição na movimentação da população do espaço rural para o espaço urbano, o que levou ao adensamento populacional nos centros urbanos em detrimento à ocupação no meio rural. Ressalta ainda que a evasão da população rural se deu e se dá, em função da precária estrutura agrária.

A realidade acima apresentada explica a aptidão agrícola de parte da massa populacional alocada nos aglomerados urbanos e sinaliza um cenário a ser incentivado pelo poder público e iniciativa privada, para a formação de um novo modelo de áreas verdes e Zonas Especiais de Interesse Social, sob a justificativa da melhoria do transporte, da mobilidade urbana, da qualidade ambiental e desenvolvimento socieconômico: o incentivo à formação da agricultura urbana e periurbana.

\section{AGRICULTURA NAS CIDADES}

A agricultura em espaços urbanos acontece no mundo desde o surgimento das primeiras cidades. A partir da década de 1990, os benefícios destas práticas na melhoria da qualidade de vida da população e do ambiente urbano chamam a atenção de organizações da sociedade civil e de governos no Brasil, que passam a incentivar a sua organização e multiplicação.

A agricultura urbana integra a produção agroecológica de alimentos, plantas medicinais e ornamentais, manejo de áreas de cerrado e mata, criação de pequenos animais, beneficiamento e comercialização solidária.

\section{OS ESPAÇOS URBANOS}

Lotes, lajes, quintais, escolas, centros de saúde, canteiros centrais e debaixo de redes elétricas (Figura 1). Esses são alguns locais onde a agricultura praticada nas cidades (Figura 2). A inovação e criatividade das pessoas mostram que é possível aproveitar os recursos e a mão-de-obra disponível para ocupar produtivamente diferentes tipos de espaços. A adaptação do conhecimento de 
origem rural ao contexto urbano, especialmente pelas mulheres, mantém vivas como conservação de sementes, a diversificação de cultivos, o manejo e uso de plantas medicinais.

As iniciativas de agricultura na cidade ampliam o acesso a alimentos frescos e saudáveis e geram oportunidade de trabalho e renda. Os quintais e hortas comunitárias ajudam a manter um espaço de convivência social e o contato com a natureza, contribui para a saúde das pessoas. O uso agrícola de espaços urbanos proporciona uma melhoria considerável ao ambiente local, seja pela diminuição da quantidade de lixo produzido, manutenção das áreas verdes, aumento da biodiversidade urbana, recuperação de áreas de risco ou embelezamento da cidade, além de favorecer para:

- descentralizar as relações comerciais favorecendo assim a melhoria do fluxo de transporte individual, coletivo e de cargas nos centros urbanos;

- harmonização paisagística na arquitetura das cidades;

- ocupação racional das áreas ociosas, impedindo a ocupação como abrigo para o uso de drogas e de meliantes;

- viabilização da finalidade social da propriedade, chamando o alerta sobre o problema da especulação imobiliária;

- povoamento de áreas remotas;

- descentralização dos investimentos públicos voltados para o saneamento e habitação;

- possibilidade da formação de mercados alternativos de produção agrecológica nas cidades;

- alternativa de renda para a população sob risco social;

- formação de espaço para a prática em educação ambiental;

- formação de espaço para conscientização sobre saúde e segurança alimentar;

- formação de espaços para a prática de terapias ocupacional, principalmente com os portadores de necessidades especiais e idosos;

- formação de espaços para a produção de alimentos saudáveis para creches, hospitais e asilos;

- favorecimento para o transporte alternativo tais como "a pé" e bicicletas, por aproximar o produtor do consumidor;

- favorecimento para boas práticas nas relações sociais;

- melhoria do trânsito nos bairros;

- formação de emprego e renda. 


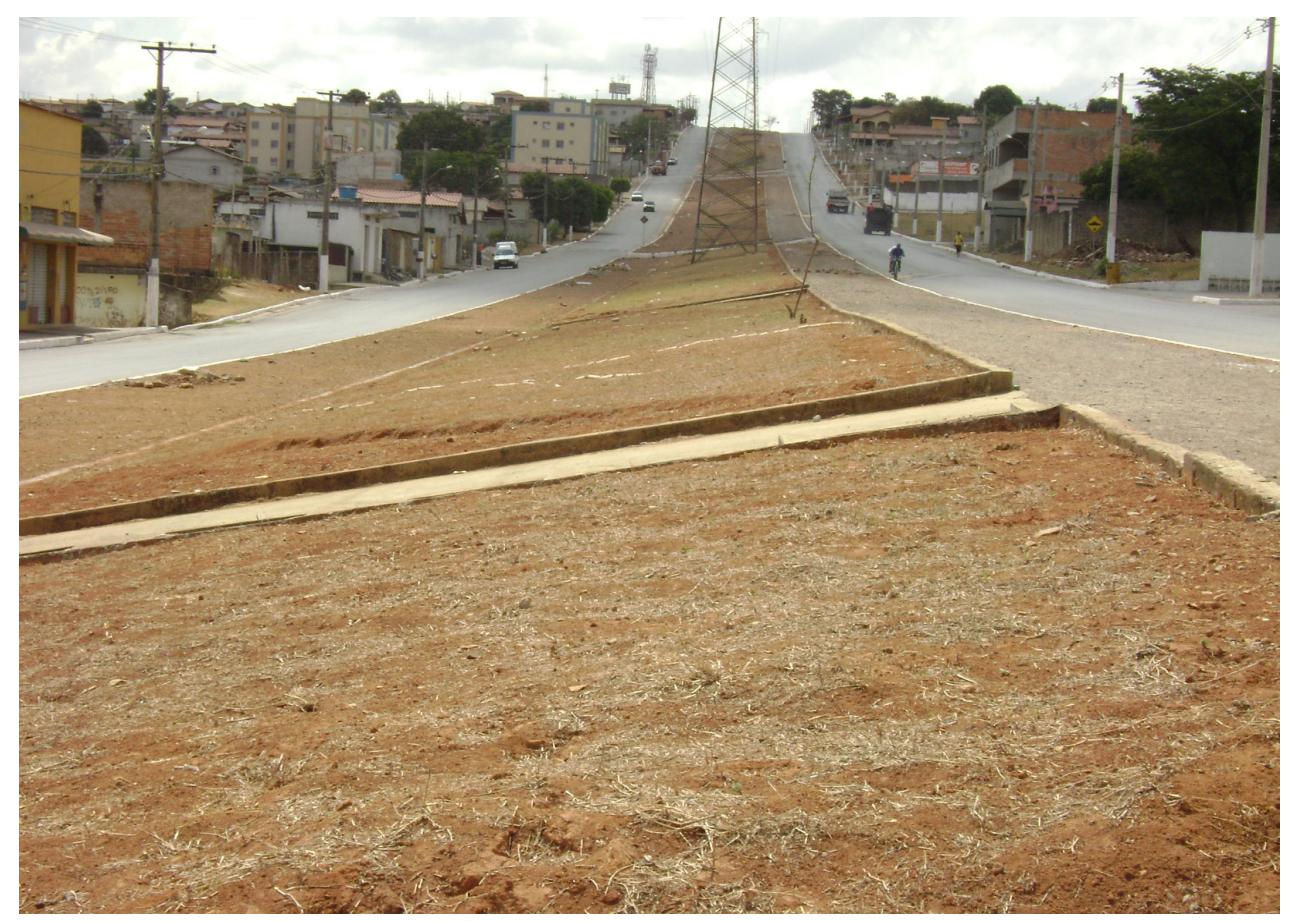

Figura 1 - Área da linha de distribuição de energia elétrica preparada para instalação de horta comunitária no bairro Felipe Cláudio em Pedro Leopoldo- MG

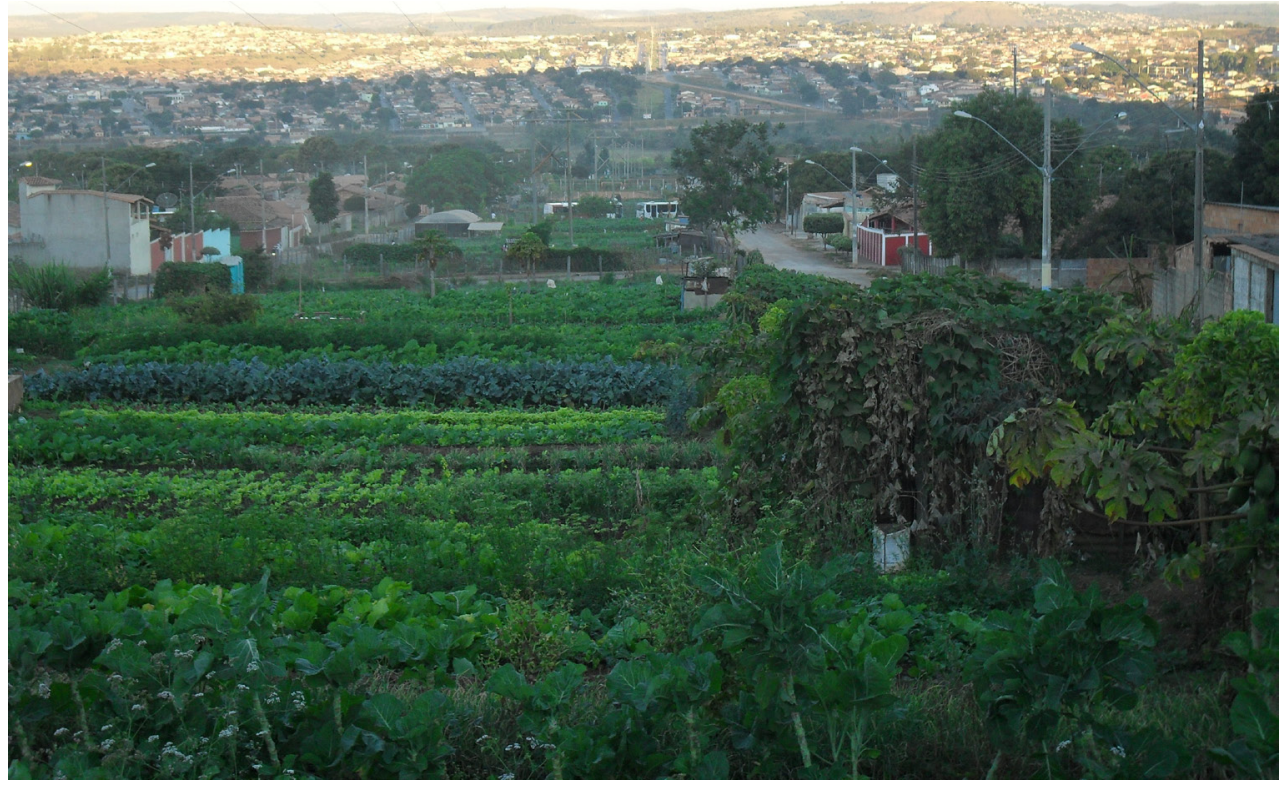

Figura 2 - área da linha de distribuição elétrica da Companhia Energética de MG (Cemig) com horta instalada ao longo de 3km, formando um mercado vivo ao lado do consumidor, no bairro Vapabuçú em Sete Lagoas - MG

A ocupação dos espaços urbanos com esse tipo de agricultura traz benefícios quantitativos e qualitativos para a população dos bairros, principalmente ao que diz respeito às questões de ambiência e economia solidária. Passa a ser um importante instrumento de gestão pública e organização social.

\section{AGRICULTURA E SUSTENTABILIDADE}

A palavra sustentabilidade é, hoje, de uso corrente entre aqueles que lidam com o desenvolvimento. No contexto da agricultura, a sustentabilidade diz respeito, basicamente, à capacidade de garantir a permanência da produtividade, ao mesmo tempo em que se mantém a base de recursos. 
O Comitê de Aconselhamento Técnico do Grupo Consultivo de Pesquisa Agrícola Internacional (Technical Advisory Commitee of the Consultative Group on International Agricultural Research - TAC/CGIAR, 1990), afirma que:

Agricultura sustentável é o manejo bem sucedido de recursos para a agricultura, de modo a satisfazer as necessidades humanas em transformação, mantendo ou melhorando, ao mesmo tempo, a qualidade do ambiente e conservando os recursos naturais.

Em toda atividade de produção agropecuária são estabelecidas relações ecológicas semelhantes às que ocorrem nos ecossistemas não manipulados pelo homem (como as matas nativas "intocadas", por exemplo). Ocorre que a intervenção do homem pela atividade econômica, como é o caso da agricultura, leva à simplificação do ecossistema pela redução do número e do volume de espécies animais e vegetais, comprometendo a biodiversidade (diversidade de espécies e formas de vida) e a estabilidade do meio ambiente (Amâncio, 1999). Com isso, o ecossistema fica mais suscetível ao aparecimento de surtos de pragas e doenças que não ocorriam anteriormente. Portanto, é fundamental que o homem conheça e compreenda as relações ecológicas (que propiciam a reprodução das diferentes formas de vida existentes na natureza) para que possa praticar a agricultura com maior consciência e racionalidade. Em outras palavras, ele transforma o ecossistema em agroecossistema e precisa conhecê-lo e manejá-lo bem para produzir melhor, com menor impacto ambiental e social, maior sustentabilidade e menor dependência de insumos externos.

Como definido anteriormente, a agricultura sustentável é o manejo bem sucedido dos recursos, de modo a satisfazer as necessidades humanas em transformação, mantendo ou melhorando, ao mesmo tempo, a qualidade do ambiente e conservando os recursos naturais. Moura Filho et al. (1994) entende que, para tanto, a agricultura precisa ser:

- ecologicamente correta, o que significa que a qualidade dos recursos naturais é mantida e a vitalidade do agroecossistema - incluindo os seres humanos, as lavouras, os animais e até os microrganismos do solo - é melhorada. Isso é mais eficazmente garantido quando o solo é manejado e quando a saúde das lavouras, dos animais e das pessoas é mantida através de processos biológicos (auto-regulação). Os recursos locais são usados de modo a minimizar as perdas de nutrientes, biomassa, energia e a evitar a poluição. A ênfase recai sobre o uso de recursos renováveis;

- economicamente viável, o que significa que os agricultores podem produzir o bastante para garantir sua auto-suficiência com uma renda que garanta a remuneração do trabalho e cubra os custos envolvidos no processo produtivo. A viabilidade econômica é medida não apenas em termos do produto agrícola direto (colheita), mas também em termos de funções, tais como a conservação dos recursos naturais e a minimização dos riscos ambientais;

- socialmente justa, o que significa que os recursos e o poder são distribuídos de modo a assegurar que as necessidades básicas de todos os membros da sociedade sejam atendidas e que sejam respeitados os direitos dos agricultores em relação ao uso da terra e ao acesso ao capital, assistência técnica e oportunidades de mercado . Todas as pessoas devem ter a oportunidade de participar na tomada de decisões, tanto na atividade rural quanto na sociedade como um todo;

- humana, o que significa que todas as formas de vida (vegetal, animal, humana) são respeitadas. Deve ser reconhecida a dignidade fundamental de todos os seres humanos e as relações e instituições devem incorporar valores humanos básicos, tais como confiança, honestidade, auto-respeito, cooperação e compaixão. A integridade cultural e espiritual da sociedade é, assim, preservada, cuidada e nutrida; 
- adaptável, o que significa que as comunidades rurais são capazes de se ajustar às condições da agricultura que sempre estão em transformação: há crescimento populacional, mudanças nas políticas governamentais, nas demandas de mercado, etc. Isso envolve não apenas o desenvolvimento de tecnologias novas e apropriadas, como também inovações em termos sociais e culturais.

Esses diferentes critérios de sustentabilidade podem entrar em conflito e podem ser vistos sob diferentes pontos de vista: o do agricultor, o da comunidade, o da nação e o do mundo. Podem haver conflitos entre as necessidades do presente e as do futuro e entre satisfazerem-se necessidades imediatas e conservar-se a base de recursos. O agricultor pode buscar melhorar sua renda através do aumento dos preços dos produtos agrícolas e o governo pode priorizar a produção de alimentos suficientes a preços que estejam ao alcance da população urbana. Assim, as escolhas devem estar sendo feitas continuamente, numa busca de equilíbrio entre interesses conflitantes. É necessário, portanto, instituições eficazes e também políticas bem deliberadas em todos os níveis - do vilarejo ao global - para assegurar o desenvolvimento sustentável.

No desenvolvimento agrícola, costuma-se dar prioridade ao aumento da produção, mas há um limite máximo para a produtividade dos ecossistemas. Se esse limite é ultrapassado, o ecossistema vai se degradar e pode, eventualmente, entrar em colapso, reduzindo-se o número de pessoas que podem sobreviver com base nos recursos restantes. Isso implica que, quando se alcançam os limites da oferta de um determinado recurso, algo precisa ser feito para atender a demanda. Por exemplo, busca de fontes de renda alternativas, emigração, redução dos níveis de consumo e controle populacional. A produção e o consumo devem ser equilibrados em um nível ecologicamente sustentável. Ainda que a sustentabilidade deva ser vista como um conceito dinâmico que permite suprir as necessidades em transformação de uma crescente população global (TAC/CGIAR, 1990), os princípios ecológicos básicos nos obrigam a reconhecer que a produtividade agrícola é finita e encontra limites.

De maneira ampla, os objetivos que se pretende alcançar com uma agricultura sustentável seriam: promover a saúde de agricultores e consumidores; manter a estabilidade do meio ambiente mediante a incorporação dos processos naturais como os ciclos de nutrientes, a fixação de nitrogênio e o controle de pragas pelos seus predadores naturais; assegurar os lucros dos agricultores no longo prazo e produzir para responder às necessidades atuais das sociedades, levando-se em conta também as gerações futuras. Diante da questão de que esses objetivos são generalizantes e difusos, é importante considerar os planos em que a sustentabilidade agrícola pode ser alcançada. Lowrance, citado por Guivant (1992), apresenta um modelo da sustentabilidade agrícola como sistema, que abrange quatro subsistemas, destacando-se em cada um deles um conjunto diferente de fatores:

- a sustentabilidade agronômica: que pode ser entendida como a capacidade que tem a menor unidade agrícola de produzir indefinidamente, respeitando os ciclos naturais e o equilíbrio dos agroecossistemas;

- a sustentabilidade microeconômica: no nível da propriedade rural, denota a capacidade do agricultor de substituir a destinação de certas áreas, segundo estejam respondendo ou não às necessidades produtivas;

- a sustentabilidade ecológica: no nível de uma região maior que a propriedade rural, refere-se à interação de florestas, fauna, flora, cursos d'água, agroecossistemas e áreas não cultivadas;

- a sustentabilidade macroeconômica: refere-se aos planos nacionais e internacionais, em que se determinam políticas das quais dependem a capacidade dos sistemas de alimentar as populações, respeitando a eqüidade entre gerações e dentro de uma geração. 
Em cada um desses planos, diversas técnicas agrícolas podem ser utilizadas, como o manejo integrado de pragas, a rotação de cultura, sistemas agroflorestais, biofertilização, etc. Algumas podem ser adotadas isoladamente, entretanto, para Guivant (1992), a unidade agrícola, assim, não ficará precisamente caracterizada como sustentável. A idéia chave é que a agricultura sustentável constitua-se num sistema integrado de diversas técnicas, sem que haja necessidade de que todas elas sejam sempre englobadas para caracterizar esses sistemas.

\section{CONSIDERAÇÕES FINAIS}

A indução da prática da agricultura urbana e periurbana nos espaços urbanos poderão complementar de forma efetiva e eficiente os Planos Diretores dos municípios, sob a alegação de uma proposta responsável e de viabilidade econômica, social e ambiental para as cidades. Caberá ao poder público e a iniciativa privada o fomento da proposta produtiva e do rearranjo espacial dos maciços urbanos. Contudo faz-se necessário o estabelecimento de diretrizes que regulamentem e disponibilizem linhas de crédito subsidiados, assistência técnica, acesso à tecnologia apropriada ao modelo de produção urbano e periurbano; caberá também melhorias da infra-estrutura de transporte para a referência local, seja a rodoviária, ciclovias, sobre trilhos ou "a pé".

As experiências de agricultura urbana, orientadas pelos princípios da agroecologia, trazem novas possibilidades para transformar a vida das pessoas e das comunidades locais. $\mathrm{O}$ fortalecimento da organização dos agricultores urbanos, uma maior articulação com outras organizações da sociedade civil e a sua capacidade de intervenção política são caminhos para a construção de cidades mais saudáveis, produtivas e solidárias. É um modelo de agricultura sustentável em meio aos aglomerados urbanos, com a proposta, para ser inserida no planejamento do Plano Diretor Municipal, visando uma alternativa viável para a formação das áreas verdes e Zonas Especiais de Interesse Social (ZEIS) nas cidades.

A partir da comprovação da viabilidade do modelo de ocupação agrária urbana e periurbana, faz-se necessário o direcionamento de políticas públicas para a sua absorção. A indicação é que a Agricultura Urbana e Periurbana sejam formalizadas pela Política Nacional de Reforma Agrária, para que os agricultores urbanos sejam enquadrados em um grupo específico, e em conseqüência, sejam contemplados com os programas da reforma agrária, agricultura familiar e mercados institucionais.

\section{REFERÊNCIA BIBLIOGRÁFICA}

AMÂNCIO, Robson. O uso de indicadores locais de desenvolvimento e a sustentabilidade da reforma agrária no cerrado do norte e noroeste de Minas Gerais. Tese de Doutorado. Seropédica: UFRRJ, 1999. 315 p.

ASSOCIAÇÃO NACIONAL DE MUNICÍPIOS E MEIO AMBIENTE. Municípios e meio ambiente: perspectivas para a municipalização da gestão ambiental no Brasil/ Arlindo Philipp Jr... [ et al.] (editores). São Paulo: 1999. Outros editores: Ivan Carlos Maglio... [et al.].

CGIAR. Farming systems research at the International Agricultural Research Centers. Rome: TAC Secretarial; Agriculture depat. FAO, 1990.

GESTÃO INTEGRADA DA MOBILIDADE URBANA. Brasil: Ministério das Cidades, 2006.

GUIVANT, J. S. A agricultura sustentável na perspectiva das ciências sociais, 1992.

MOURA FILHO, J. A. de et al. Relatório de Pesquisa: Transformações recentes na agropecuária mineira. Lavras, UFLA, 1994.

PLANO DIRETOR ESTRATÉGICO. São Paulo; Cartilha de Formação, 2003.

PONS, JMS.; REYNÉS, M.R.M. Geografia de los transportes. Universidad de lês Illers Balears, 2004.

PRESIDÊNCIA DA REPÚBLICA. Lei n⿳010257: Estatuto das Cidades. 07/2001. 
RIBEIRO, Mauricio Andrés. Et allí. Município e Meio Ambiente. Belo Horizonte: Fundação Estadual do Meio Ambiente, 1995. 74p. (Manual de saneamento e proteção ambiental para os municípios).

SANCHES Junior, Paulo Fernandes. Logística de carga urbana: uma análise da realidade brasileira. Campinas, SP: tese de doutorado, 2008.

TRANSPORTE E MEIO AMBIENTE. (cadernos técnicos, 6) São Paulo: ANTP/BNDES,2007.

Trabalho enviado em janeiro de 2013

Trabalho aceito em março de 2013 